\title{
Management of Ano-Rectal Malformations in a Tertiary Level Children's Hospital of Nepal
}

\author{
Thapa $\mathrm{B}^{1}$, Basnet $\mathrm{B}^{2}$, Pun $\mathrm{MS}^{3}$, Thapa $\mathrm{A}^{4}$ \\ ${ }^{1} \mathrm{Dr}$. Bijay Thapa, MBBS, MS, Registrar Paediatric \\ Surgeon, ${ }^{2} \mathrm{Dr}$. Balmukunda Basnet, MBBS, MS, \\ Paediatric Surgeon, ${ }^{3}$ Dr. Madhusudan Pun, MBBS, MS, \\ Head of Department and Consultant Paediatric Surgeon, \\ ${ }^{4}$ Dr. Anupama Thapa, MBBS, MS, Registrar Paediatric \\ Surgeon. All from the department of Paediatric Surgery, \\ Kanti Children's Hospital, Maharajgunj, Kathmandu, \\ Nepal.
}

\section{Introduction}

no-rectal malformations are congenital Amalformations in which the distal part of the hindgut fails to develop or develops partially leading to various anomalies. Imperforated anus is one of the commonest congenital ano-rectal malformation in newborn with an incidence of 1 per 4000-5000 live births. Early assessment and accurate diagnosis of the type of anorectal malformation are essential for determining which type of surgery is needed. In addition to the clinical diagnosis different imaging techniques are used like invertogram or prone cross table lateral film, ultrasonography and $\mathrm{MRI}^{1,2,3,4,5}$.

The main aim of the management of ARM is to relieve intestinal obstruction if present; restore anorectal continuity with optimal sphincter function, early postnatal establishment of brain-defecation reflex, reduction of the physical and psychological stress to the family ${ }^{6,7,8}$.

Wingspread classification in 1984 proposed a working formulation in which this anomaly is classified into three types as high, intermediate and low depending upon the site of the blind rectal pouch in relation to the levator and puborectlis muscle. This classification is more precisely defined now in combination with an associated fistula ${ }^{9,10,11,12}$.

Fistula are found in $80-90 \%$ cases of ARM between the lower end of rectum and the perineum, female

\begin{abstract}
Introduction: Ano-rectal malformation (ARM) comprises a wide spectrum of diseases that involves the distal anus and rectum as well as the urinary and genital tracts. The factors that need to be considered during treatment are the type of anomaly, associated anomalies and patients general condition. The aim of this study is to analyze the types of anorectal malformations and their management in a tertiary level children's hospital. Materials and Methods: The medical records of patients with the diagnosis of anorectal malformation managed in the hospital during a period of January 2009 to January 2014 were reviewed. Results: There were 187 cases of ARM $126(67.37 \%)$ males and $61(32.62 \%)$ females. High/Intermediate type was 129 (68.98\%). Low ARM was 58 (31.01\%). In male high type ARM with recto-urethral fistula was seen in 60 (47.61\%). ARM with Rectovestibular fistula(RVF) was seen in 40 (65.5\%) female. High and intermediate ARMs were managed initially with colostomy and low ARM with primary anoplasty. ARM with rectovestibular fistula in females were managed with Anterior Sagittal Anorectoplasty without colostomy. Common cloaca in female was managed initially with colostomy followed by posterior sagittal ano-recto-vagino-urethroplasty. Colostomy closure was done after adequate size of anus was achieved with anal dilation. Conclusion: The type of ARM in newborn is diagnosed by perineal examination and X-rays. Low type ARM was managed by primary surgery without colostomy. High anomaly and complex defect was treated with stage surgeries.
\end{abstract}

Key words: Anorectal malformation, anoplasty, colostomy, fistula.

genitalia or urinary tract. Anorectal malformations can also be associated with other external and internal anomalies especially of genitourinary system ${ }^{13,14}$.

\section{Address for correspondence \\ Dr. Bijay Thapa \\ Registrar Paediatric Surgeon \\ Kanti Children's Hospital \\ Kathmandu, Nepal \\ Email: bijaytapa@hotmail.com}

\section{How to cite this article ?}

Thapa B, Basnet B, Pun MS, Thapa A. Management of AnoRectal Malformations in a Tertiary Level Children's Hospital of Nepal. J Nepal Paediatr Soc 2013;33(3):196-200. 
High type is more common in male while intermediate more in female. Low type ARM is corrected surgically in a single stage at neonatal period. Colostomy is performed in cases of intermediate and high types followed by anorectoplasty at the later stage and then colostomy closure. With early diagnosis, management of associated anomalies and efficient surgical repair patient have good functional outcome ${ }^{15,16,17}$.

\section{Materials and Methods}

This was a retrospective study where the medical records of patients with the diagnosis of anorectal malformation (ARM) admitted and managed in Kanti Children's Hospital, Department of Surgery, between January 2009 to January 2014 were reviewed.

There were total of 187 new cases of ARM managed during the study period. Three hundred and twenty five different surgeries were performed. The children included in this study were those having anorectal malformation in the neonatal period, those admitted for corrective surgery and those with colostomy closure. The data on sex, types of anomalies and surgical procedures were analyzed. Wingspread Classification and location of perineal fistula was used to diagnose ARM as high, intermediate and low type. Prone cross table lateral film was done in children without visible fistula to diagnose the types of ARM. Abdominal ultrasound was done to see any other abdominal pathology associated with ARM like genitourinary anomaly.

\section{Results}

Among the 187 new cases of ARM,126 (67.37\%) male and 61 (32.62\%) female were operated in their first admission. Among them 139 were neonates, male 126 and female 13.

Table 1: Sex distribution children with ARM.

\begin{tabular}{|c|c|}
\hline Sex & No (\%) \\
\hline Male & $126(67.37 \%)$ \\
\hline Female & $61(32.62 \%)$ \\
\hline Total & $\mathbf{1 8 7 ( 1 0 0 \% )}$ \\
\hline
\end{tabular}

ARM- anorectal malformation

Table 2: Types of ARM and sex distribution.

\begin{tabular}{|c|c|c|c|}
\hline Type & Male & Female & Total (\%) \\
\hline High & \multirow{2}{*}{76} & $\begin{array}{c}5+8 \\
\text { (cloacae) }=13\end{array}$ & $\begin{array}{c}129 \\
(68.98 \%)\end{array}$ \\
\cline { 3 - 4 } & & $40(\mathrm{RVF})$ & \\
\hline Intermediate & & 8 & $58(31.01 \%)$ \\
\hline Low & 50 & $\mathbf{6 1}$ & $\mathbf{1 8 7}(\mathbf{1 0 0 \% )}$ \\
\hline Total & $\mathbf{1 2 6}$ & & \\
\hline
\end{tabular}

Table 3: Types of ARM in neonates.

\begin{tabular}{|c|c|c|c|}
\hline Sex & High/inter & Low & Total \\
\hline Male & 76 & 50 & 126 \\
\hline Female & 5 & 8 & 13 \\
\hline Total & $\mathbf{8 1}$ & $\mathbf{5 8}$ & $\mathbf{1 3 9}$ \\
\hline
\end{tabular}

Seventy six $(60.31 \%)$ of total males patients had high and intermediate type ARM. All of them were managed by protective sigmoid colostomy and discharged. Fifty (39.68\%) male patients had low type ARM and managed by primary anoplasty.

Table 4: Sex distribution in relation to fistula

\begin{tabular}{|c|c|c|c|}
\hline Sex & Fistula & Without fistula & Total \\
\hline Male & 110 & 16 & 126 \\
\hline Female & 56 & 5 & 61 \\
\hline Total & $\mathbf{1 6 6 ( 8 8 . 7 7 \% )}$ & $\mathbf{2 1 ( \mathbf { 1 1 . 2 9 } \% )}$ & $\mathbf{1 8 7 ( \mathbf { 1 0 0 } \% )}$ \\
\hline
\end{tabular}

A hundred and ten (87.30\%) of total male ARM patients had fistula. Among them 60 (78.94\%) were in high and intermediate type ARM with rectourethral fistula. Only $16(21.05 \%)$ were without fistula. A total of $50(39.68 \%)$ male had low type ARM with fistula in perineum and managed by primary anoplasty.

Table 5: Distribution of male defects in relation to fistula.

\begin{tabular}{|l|c|}
\hline Type of defect & No (\%) \\
\hline ARM $(\mathrm{H} / \mathrm{l})$ with fistula(urethral) & $60(47.61 \%)$ \\
\hline ARM $(\mathrm{H} / \mathrm{l})$ without fistula & $16(12.69 \%)$ \\
\hline Ano-cutaneous/ perinea fistula(L) & $50(39.68 \%)$ \\
\hline Total & $\mathbf{1 2 6 ( 1 0 0 \% )}$ \\
\hline
\end{tabular}

The most common anomaly in female was ARM with rectovestibular fistula which comprises 40 (65.57\%) of total female child. They all were managed by primary anterior saggital anorectoplasty (ASARP) without colostomy. High type ARM in female without fistula was only seen in 5 (8.19\%). Common cloaca were seen in 8 $(13.11 \%)$ and were managed by colostomy and planned for posterior sagittal ano-recto-vagino-urethroplasty (PSARVUP) later. Similar to males 8 females with low anocutaneous and perineal fistula were managed by anoplasty.

Table 6: Distribution of female defects in relation to fistula

\begin{tabular}{|l|c|}
\hline Type of defects & No (\%) \\
\hline ARM $(\mathrm{H} / \mathrm{l})$ without fistula & $5(8.19 \%)$ \\
\hline ARM + Rectovestibular fistula (I) & $40(65.5 \%)$ \\
\hline ARM with common cloaca (H) & $8(13.1 \%)$ \\
\hline ARM Ano-cutaneous/perineal fistula (L) & $8(13.1 \%)$ \\
\hline Total & $\mathbf{6 1 ( 1 0 0 \% )}$ \\
\hline
\end{tabular}


Distal colostogram was done in all patients with colostomy prior to definitive surgery. Posterior sagittal anorectoplasty (PSARP) was done in all high or intermediate types and Abdomino Posterior anorectoplasty was done in those high types in which perineal approach was not enough. Colostomy closure was done after two three months of definitive surgery. Anal dilation was done in all patients two weeks postoperatively until the desired size of anus.

Table 7: Associated anomalies in ARM

\begin{tabular}{|l|c|c|c|}
\hline \multicolumn{1}{|c|}{ Associated anomalies } & Male & Female & Total \\
\hline Inguinal hernia & 4 & 2 & 6 \\
\hline Undescended testes & 3 & & 3 \\
\hline Hypospadias & 8 & & 8 \\
\hline Epispadias & 1 & & 1 \\
\hline Renal agenesis & 2 & & 2 \\
\hline Ectopic kidney & 1 & & 1 \\
\hline Hydronephrosis & 1 & 5 & 6 \\
\hline Sacral agenesis & 3 & & 3 \\
\hline $\begin{array}{l}\text { Esophageal atresia with } \\
\text { tracheal fistula }\end{array}$ & 1 & 1 & 2 \\
\hline Cleft lip palate & 2 & & 2 \\
\hline Down syndrome & 2 & & 2 \\
\hline \multicolumn{1}{|c|}{ Total } & $\mathbf{2 8}$ & $\mathbf{8}$ & $\mathbf{3 6}$ \\
\hline
\end{tabular}

Table 8: Different surgeries performed in ARM

\begin{tabular}{|l|c|c|c|}
\hline Category & Male (\%) & Female (\%) & Total \\
\hline $\begin{array}{l}\text { Newborn } \\
\text { anoplasty (L) }\end{array}$ & 50 & 8 & 58 \\
\hline $\begin{array}{l}\text { Newborn } \\
\text { colostomy (H/I) }\end{array}$ & 76 & 5 & 81 \\
\hline $\begin{array}{l}\text { Post Newborn } \\
\text { Colostomy }\end{array}$ & 0 & 40 & 40 \\
\hline For ASARP & 34 & 12 & 46 \\
\hline For PSARP & 5 & 0 & 5 \\
\hline $\begin{array}{l}\text { Abdomino-PSARP } \\
\text { (H) }\end{array}$ & 0 & 8 & 8 \\
\hline For PSARVUP & 34 & 22 & 56 \\
\hline $\begin{array}{l}\text { For colostomy } \\
\text { closure }\end{array}$ & 6 & 0 & 6 \\
\hline Redo PSARP & 227 & 98 & 325 \\
\hline Redo ASARP & & 0 & 2 \\
\hline Redo Anoplasty (L) & 2 & 8 & 8 \\
\hline Total & & & \\
\hline
\end{tabular}

\section{Discussion}

Anorectal malformation is one of the most common congenital anomalies encountered at birth with an absent anus or ectopic anus which is more common in males $^{1,2}$. In our study there were $126(67.37 \% \%)$ males and $61(32.62 \%)$ females with male to female ratio of
$2: 1$. This figure is close to $65 \%$ male given in a series by Penaw $^{5}$.The Alberta congenital anomalies surveillance system 1990-2004 shows an overall rate with male predominance $(1.7: 1)^{8}$.

The correct and timely intervention is crucial to determine the immediate future of the child. The basic principles in the management are to prevent or relieve intestinal obstruction, to establish normal defecation and to preserve or restore normal urogenital function. The plan of management depends upon whether these objectives can be realized simultaneously i.e. by single definitive surgical procedure or in stages. Low type anomalies in our series including female with rectovestibular fistula were all managed by single definitive surgeries. Others with high, intermediate and complex anomaly were managed with colostomy.

Majority of patients with ARM present early in the neonatal period. Patridge and Gough have reported that $64.9 \%$ patients were neonates at presentation ${ }^{8}$. In our series we had higher incidence 139 (74.33\%) of neonatal presentations. Those who presented late were mostly female with rectovestibular fistula and cloaca that were mistaken as normal anus.

Anorectal malformations are used to be classified into three main types depending on whether the blind end is above, within, or below the sphincter muscle complex (Wingspread classification).This classification has now been done with association with male or female to the site of associated fistula. All cases in our series without visible fistula underwent prone cross table lateral film and classified into three types with Wingspread classification. In females ARM may be associated with fistula in the perineum or vaginal vestibule and rarely to vagina. In males this is associated with fistula to the perineum or urethra or bladder neck. That is the reason perineal examination is very important in anorectal malformation $^{9,10}$.

Invertogram used to be the choice of radiologic investigations to approximate high, intermediate and low anomalies. But now it has been replaced by prone cross table lateral film as it is much easier and less time consuming due to position in prone, hips flexed in genupectoral position. Patient also feels calm and relaxed in this position showing the full extent of the rectal gas shadow. In our series all ARM cases without visible fistula underwent prone cross table lateral film and classified. Radiological evaluations do not show the actual anatomy before 24 hours because the rectum is collapsed and it takes time for colonic gas to overcome the muscle tone of the sphincter that surrounds the lower part of rectum. Therefore radiological evaluation done before this time may show very high rectum and yield 
false diagnosis ${ }^{11,12}$. Few cases in our series referred from other local hospital underwent invertogram before 24 hours showed high ARM. After perineal examination and repeat xray after 24 hours, these showed to be of low types and managed in a single stage.

Ultrasound is also used in many centers to differentiate the types. Hans $\mathrm{P}$ Haber et all in their series has measured the distance between the distal blind rectal pouch and the perineum. They classified as high or intermediate with the distance greater than $1.5 \mathrm{~cm}$ and as low type with less than $1.5 \mathrm{~cm}^{12}$. In our study we are only able to do in 6 cases as ultrasonography is not always feasible in emergency basis. Intra-operative findings of high and low type according to ultrasound measurement in all these six cases were similar.

Pena has reported the presence of the fistula in female patient to be over $90 \%$. In Liverpool series 83 out of 98 had fistula in males, 51 out of the 53 had fistula in females ${ }^{5,13}$. In our series 110 males out of 126 and 56 females out of 61 had fistula seen pre and intraoperatively. This shows ARM have fistula with different variants like vestibular, vaginal, anocutaneous and vesicular in females and urethral, vesicular, anocutaneous in male.

The presence of an anocutaneous/perineal fistula indicates the presence of the low type of ARM Neonates with this type of phenotype do not need further diagnostic procedures on the anorectum and undergo a surgical procedure in the first day of life. In our study 50 males and 8 females had low anomaly and were managed by primary anoplasty (cut back anoplsty, Y-V anoplasty, minimal posterior sagittal anoplasty PSAP). In the children's memorial hospital series of 216 ARM patients $47 \%$ had low anomalies and in Liverpool series 74 out of 151 had low anomalies ${ }^{13}$. Low ARM is associated with well developed rectum, anal canal, sphincters and sensory receptors with good postoperative results.

In our series, male $76(60.3 \%)$ and female13 $(21.31 \%)$ with high or intermediate ARM were primarily managed by colostomy and later with posterior sagittal anorectoplasty PSARP. Though the definitive surgery PSARP in advanced centers are done at early infancy. We prefer at around one year of age as the chances of sepsis is higher in early age in our set up, anatomy is clearer while seperating fistula. Colostomy closure is done after adequate size of anus is reached with anal dilation as many cases come in follo-up without regular anal dilation. Pena and deVires in 1982 gave description of PSARP and anal dilation which is now a landmark of surgery of high ARM ${ }^{14,15}$.

Although three stage surgeries have been in practice for high ARM, recently many authors have practice doing primary PSARP ${ }^{16,17,18}$. A. Mirshemirani et all in their series of 30 newborns with high ARM underwent primary PSARP and showed it to be safe and effective in newborns ${ }^{19}$. In Kanti Children's hospital, Nepal we are not yet able to do as most of the cases come late, dehydrated, with abdominal distension and post operative care for primary PSARP is difficult due to high chance of wound infection.

The most common variety of ARM in female in our study was rectovestibular fistula 40 (65.5\%). This anomaly was also done as three stage surgeries before. After the introduction of Primary anterior sagittal anorectoplasty ASARP in 1988, it has become a standard method. All of our cases were managed by primary ASARP and the result was good ${ }^{20,21}$.

In the female the number of opening in the perineum is highly significant. Three openings means that the problem can be managed from perineum as rectovestibular fistula in our series are all managed in single stage while the presence of two or only one opening (cloaca) means staged surgery.

Various studies have reported the incidence of associated anomalies with ARM to be 30 to $70 \%$ cases. The VACTERL syndrome is a specific groups of vertebral, anal, cardiac, tracheal, esophageal, and renal and limb anomalies. An overall incidence of $50 \%$ has been reported by De Vries. Stephens and Smith found that $60.6 \%$ had one or more associated anomalies. In our series only $36(19.2 \%)$ cases had associated anomaly ${ }^{22,23}$. This low incidence in our series may be due to poor screening as our patients undergo the initial surgical treatment without detailed work up for associated anomalies soon after their admission It is because ultrasound, echocardiogram and other screening investigations are not available in our emergency services.

Associated congenital anomalies in neonates with ARM is important as survival and prognosis depends upon its number and severity ${ }^{24}$. In our series those cases of ARM associated with esophageal atresia, down syndrome and 2 very low birth weight with suspected congenital heart disease all expired.

\section{Conclusion}

Male patients predominate in our study which shows the incidence is high in males. High type anorectal malformations are more frequent in males whereas intermediate type with rectovestibular fistula is common in femlae. Anorectal malformations can be classified clinically with prone cross table lateral X-ray film and the management protocol can be made on this basis. In males low anomalies are managed with single 
stage perineal surgery while intermediate and high anomalies require preliminary colostomy. In females low and intermediate type rectovestibular fistula can be done through perineal route without colostomy while high anomalies require staging.

Acknowledgements: None

Funding: None

Conflict of Interest: None

Permission from IRB: Yes

\section{References}

1. AK Wakhlu. Management of congenital anorectal malformations. Indian Pediatr 1995;32: 1239-42.

2. H H Nixon. Review of anorectal anomalies. J R Soc Med 1984;77,3, 27-9.

3. Kamal JS, Rayes OM, Kurdi MO. A collective review of cases with imperforate anus managed in a teaching hospital. Saudi J health Sci 2012; 1: 122-5.

4. A E Archibong,I M Idika. Results of treatment in children with anorectal malformations in Calabar Nigeria. South African J Sci 2004;42:3,88-90.

5. Pena A, Marc AL. Anorectal malformation. In Grosfeld JL,Oneil JA,Coran AG.Pediatric surgery, Philadelphia.Mosby 2006:1566-89.

6. Bhargava P, Mahajan J K, Kumar A. Anorectal malformations in children. $J$ Indian Assoc Pediatr Surg 2006;11:136-9.

7. S.W. Moored. Sidler. Anorectal malformations in Africa. South African J Sci 2005;4:174-5.

8. Lowry RB, Sibbald B, Bedard T.Stability of prevalence rates of anorectal malformations in Alberta congenital anomalies surveillance system1990-2004. J Pediatric Surg 2007; 42(8);1417-21.

9. Partridge JP, Gough MH.Congenital abnormalities of anus and rectum. Br J Surg 1961, 49: 37-50.

10. Gupta DK. Anorectal malformations-Wingspread to Krickenbeck. J Indian Assoc Pediatr Surg 2005;10:75-7.

11. K.L. Narasimharao, G R Prasad, S Katariya. Prone cross-table lateral view: An alternative to the invertogram in imperforate anus. Am $J$ Radiol 1983;140:227-29.
12. Hans P. Haber, Guido Seitz, Steven W. Warmann. Transperineal sonography for determination of the type of imperforate anus. Am $J$ Radiol 2007; 189:1525-29.

13. Cook RCM. Anorectal malformations.In; Lister $\mathrm{J}$, Irene M, editors. Neonatal surgery.london; Butterworth and co Itd; 1990.p.547-66.

14. De Vires P, Pena A. Posterior sagittal anorectoplasty. J Pediatr Surg 1982;17;638-43.

15. Kifayat Khan. Anorectal malformation: Functional outcome of posterior sagittal anorectoplasty. J Postgraduate Med Inst 2008;22(4):304-308.

16. Essam A Elhalbay.Primary repair of high and intermediate anorectal malformation in neonates. Annals Pediatr Surg 2006;2:117-122.

17. Aamir Hanif Khan, Mukhtar Hussain, Iram Uzma Khalid. Posterior sagittal anorectoplasty in anorectal malformations. Ishtar Med J 2009; 1(1):14-18.

18. Leva E,Macchini F,Arnoldi R,Di Cesare A et al.Single stage surgical correction of anorectal malformation associated with rectourinary fistula in male neonates. J Neonatal Surg 2013;2(1):3.

19. A. Mirshemirani,J. Kouranioo,M Rouzrokh.Primary posterior sagittal anorectoplasty without colostomy in neonates with high imperforated anus. Acta Medca Iranica 2007;45(2):121-25.

20. Zanotti AM. Development of a new operation for the repair of rectovestibular fistulas in females with anorectal malformations. I Pediatr Surg 1993;28(2):279.

21. Naima Zamir, Farhat Masood Mirza et al.Anterior sagittal approach for anorectal malformation in female children: early results.Journal of the college of physicians and surgeons Pakistan.2008; 18(12):763-767.

22. Stephens FD. Imperforate rectum. A new surgical technique. Med Austra 1953; 1: 202-9.

23. Alireza Mirshemirani, Javad Ghorobi, Mohsen Roozroukh.Urogenital tract abnormalities associated with congenital anorectal malformations. Iran J Pediatr. 2008; 18(1): 171-174.

24. A Kumar, S Agrawala, M Srinivas et al. Anorectal malformations and their impact on survival. Indian journal of pediatrics, 2005; 72(12): 1039-1042. 